\title{
Susceptibility Status of Anopheles gambiae s.l. (Diptera: Culicidae) from Cabbage Growing Areas Associated with Pyrethroid and Organophosphate Use in Accra, Ghana
}

\author{
O. A. Achonduh ${ }^{1}$, W. S. K. Gbewonyo ${ }^{1,2 *}$, D. A. Boakye ${ }^{1,3}$ and M. D. Wilson ${ }^{1,3}$ \\ ${ }^{I}$ African Regional Postgraduate Programme in Insect Science (ARPPIS), University of Ghana, \\ Legon, Accra, Ghana \\ ${ }^{2}$ Department of Biochemistry, University of Ghana, Legon, Accra, Ghana \\ ${ }^{3}$ Noguchi Memorial Institute for Medical Research, University of Ghana, Legon, Accra Ghana \\ *Corresponding author; E-mail:wsgbew@ug.edu.gh
}

\begin{abstract}
Resistance in malaria vectors is likely to be caused by the massive use of insecticides in agriculture. Anopheles gambiae s.l. collected from breeding grounds in two cabbage growing areas within Accra were assessed for levels of resistance to $0.75 \%$ permethrin, $0.05 \%$ deltamethrin, $5 \%$ malathion and $4 \%$ DDT using standard WHO susceptibility test kits. Pyrethroid and organophosphate residue levels in soil and run-off water from these cabbage farms were determined and possible association between resistance and residue levels were established. Compared to the susceptible 'Kisumu' strain, both Korle-Bu and Airport populations were highly resistant to DDT and gave resistance levels which were over nine-fold for permethrin and over 2.5-fold for deltamethrin. Both wild and susceptible populations showed full susceptibility to malathion. The $\mathrm{S}$ and $\mathrm{M}$ forms of A. gambiae s.s. were found to occur in sympatry in the two study sites with a higher frequency of $S$ form in the Airport area. Toxicity testing of extracts of soil and run-off water from these cabbage farms, using brine shrimp lethality tests, showed high level of toxicity, indicative of the presence of residues of insecticides. Differential fractionation of these extracts using solid phase extractor (SPE) suggests that the bulk of residues in these extracts may be pyrethroids and organophosphates. No correlation was observed between either residue levels or residual bioactivity in soil and run-off water, and resistance levels in $A$. gambiae s.l. populations, collected from breeding grounds within the farms under investigation. It is proposed that resistance in A. gambiae larvae in these breeding sites contaminated with agricultural insecticides may have occurred over time due to continuous exposure to sub-lethal doses.
\end{abstract}

\section{Introduction}

Resistance to insecticides has become a limiting factor in the use of these compounds in the control of many insect pests or vectors. Many examples have shown that resistance of malaria vectors to insecticides has most likely been due to massive use of insecticides in agriculture, especially in cotton and rice production (Lacey \& Lacey, 1990; Chandre et al., 1999a; Diabeté et al., 2002). Moreover, more than $90 \%$ of all insecticides produced have been used for agricultural purposes, and this has created serious problems for mosquito control programmes (Roberts \& Andre, 1994).

When pesticides are applied to protect crops from pests and diseases, only around $15 \%$ of the preparation hit the target. The rest is distributed in the soil and air (Varca, 2002). It is known that most of the applied pesticides are subject to many transport and conversion processes. Thus, they do not remain at their target site but often enter aquatic environments via soil percolation, air drift or surface run-off, affecting abundance and diversity of non-target species, and produce complex effects on the ecosystems, thus, altering trophic interactions (Rand et al., 1995).

In Ghana, cabbage cultivation may be considered a major contributor to pesticide contamination of the environment in the urban areas. Due to increasing demand for cabbage, especially in urban areas, cabbage growers in Ghana have resorted to monoculture and intensive cultivation of the crop. This practice has led to increased insect pest populations and manifestation, thus, affecting optimum yield. Additionally, with the all year round suitable environmental conditions for survival and development, pest outbreaks occur with enormous

West African Journal of Applied Ecology, Vol. 12, 2008 
damage (Afun et al., 1992) on cabbage farms. The growers, in an attempt to protect their crop and investment, resort to the use of insecticides to control insect pests. For example, BrempongYeboah (1992) observed that cabbage growers in the Accra Plains used large quantities of insecticides (mostly organophosphates and pyrethroids) and concoctions against the diamondback moth. Increased frequency of application ranging from 2-3 days interval was also observed.

Although there are positive benefits from agriculture, the use of pesticides for agricultural purposes has a direct impact on human health through increased human exposure to agrochemicals, or increased exposure to vectors of diseases, such as malaria (SIMA, 2003). An important negative impact is the role of agrochemicals run-offs in the evolution of insecticide resistance in Anopheles mosquitoes that transmit malaria parasites (SIMA, 2003). Work done in Burkina Faso by Diabaté et al. (2002) showed that agricultural use of insecticides was involved in the incidence of resistance to permethrin and DDT in field populations of mosquitoes. Klinkenberg \& Boelee (2002) reported that urban agriculture, by way of open-space irrigated vegetable farms, may lead to the creation or extension of breeding sites for the vector of malaria, thereby, influencing transmission of malaria in Ghana.

Pools of water which serve as breeding sites may be run-offs from sprayed farms and may contain insecticide residues. Moreover, there have been reports of pyrethroid resistance in populations of A. gambiae s.s. in Accra (Adasi et al., 2000; Adeniran, 2002). The present study, carried out in Accra between September 2004 and March 2005, was aimed at investigating resistance in A. gambiae s.l. vectors of malaria in and near cabbage farms, determining insecticide residue levels and establishing possible association between resistance development and residue levels.

\section{Study area}

\section{Materials and methods}

The study area was within the Accra metropolitan area in Ghana. Accra is situated in the driest coastal plains of Ghana with a mean annual rainfall ranging between $740 \mathrm{~mm}$ and $890 \mathrm{~mm}$. The mean monthly temperature is between $25^{\circ} \mathrm{C}$ and $30^{\circ} \mathrm{C}$, and the relative humidity ranges between $65 \%$ and $75 \%$ (Dickson \& Benneh, 1988). Samples were collected from cabbage farms in Korle$\mathrm{Bu}\left(05^{\circ} 32^{\prime} \mathrm{N}, 00^{\circ} 13^{\prime} \mathrm{W}\right)$ and Airport Residential Area $\left(05^{\circ} 35^{\prime} \mathrm{N}, 00^{\circ} 11^{\prime} \mathrm{W}\right)$. Irrigated urban agriculture by way of open-space irrigated vegetable farming is practiced in these areas. The cabbage farms were selected on the basis of availability of mosquito breeding sites located within or near the farm. Mosquitoes were collected as larvae or pupae from breeding grounds inside cabbage farms and brought to the insectary for emergence of adults. A susceptible A. gambiae s.s. from Kisumu (Kenya) was provided by the Noguchi Memorial Institute for Medical Research and used as the reference strain.

Bioassays were carried out for wild and susceptible populations using standard WHO susceptibility test for $0.75 \%$ permethrin, $0.05 \%$ deltamethrin, $5 \%$ malathion and $4 \%$ DDT (WHO, 1998). DDT (4\%) was used to check for cross-resistance in the same population. Non-blood fed female mosquitoes aged between 2-5 days old were used. Twenty-five adult female mosquitoes were exposed to insecticide-impregnated papers purchased in standard testing tubes from $\mathrm{WHO}$, and the number of mosquitoes knocked-down was recorded for up to $60 \mathrm{~min}$. at an interval of 10 min. All tests were undertaken at $25 \pm 2{ }^{\circ} \mathrm{C}$ and $55-78 \%$ relative humidity, and a natural photoperiod was maintained. They were then transferred to clean holding tubes where $10 \%$ sucrose was provided on cotton wool, and mortality determined $24 \mathrm{~h}$ after exposure. Control mosquitoes were exposed to papers impregnated only with olive oil and each test was replicated four times.

Mosquitoes used in bioassays were identified to the species level using polymerase chain reaction, following the method of Scott et al. (1993). A. gambiae s.s. mosquitoes were further 
identified as $\mathrm{M}$ or $\mathrm{S}$ form by polymerase chain reaction - restriction fragment length polymorphism, using the method of Fannello et al. (2002).

\section{Isolation of insecticides residues}

Insecticide standards were selected based on the insecticide use pattern for cabbage cultivation reported in Accra. Standards of permethrin, deltamethrin, cypermethrin, chlorpyrifos, pirimiphosmethyl were purchased from EQ Laboratories Inc., Atlanta, USA. Purity of standards was $100 \%$. Stock solutions of standards were prepared in hexane.

Run-off water was collected in duplicates into 2.5 litre Winchester bottles from mosquito breeding sites inside cabbage farms and immediately transported to the laboratory. Samples were filtered and concentrated to $500 \mathrm{ml}$, using Eyela rotary vacuum evaporator (Rotavap) at $40{ }^{\circ} \mathrm{C}$. Soil samples were collected from $0-15 \mathrm{~cm}$ of surface soil in duplicates at various points on the cabbage farm during water sampling, and transported immediately to the laboratory in bottles wrapped in aluminum foil and then air-dried for $48 \mathrm{~h}$. The soil was then ground in a mortar to render it fine using a pestle and then sieved using a 1-mm sieve. Both soil and water were stored separately at $4{ }^{\circ} \mathrm{C}$ till ready for use.

\section{Extraction and clean up of residues}

Soil samples. The extraction procedure of Singh et al. (1999) was used with minor modifications. Air-dried soil (10 g) was extracted in $25.0 \mathrm{ml}$ hexane-ethyl acetate solution $(9: 1)$ with stirring for $12 \mathrm{~h}$. The solvent phase was carefully taken out and extraction was repeated with fresh solvent. The two fractions were pooled and centrifuged at 3000 r.p.m. for 5 min, and the supernatant transferred into clean 100-ml flasks containing anhydrous sodium sulphate to remove any moisture present.

Water samples. Extraction procedure of Handa et al. (1999) was used with minor modifications. Fifty millilitres of run-off concentrate was taken into a separating funnel in duplicates and shaken with $50 \mathrm{ml}$, hexane:ethyl acetate mixture $(9: 1)$ for 2-3 min. The organic phase was carefully transferred into clean flasks. The process was repeated three times with fresh solvents and all three extracts were pooled and transferred into clean flasks containing anhydrous sodium sulphate. Both soil and water extracts were concentrated to $5 \mathrm{ml}$ using Buchi Rotavapour (Buchi, Switzerland) at $40^{\circ} \mathrm{C}$, transferred into clean pre-weighed vials and evaporated under a stream of nitrogen gas to dryness and then reconstituted in hexane. Differential fractionation and clean up of extracts was done using $\mathrm{C}_{18}$ solid phase extraction (SPE) columns. Methanol, ethyl acetate and hexane were selected as eluting solvents, based on the differences in polarity. The SPE columns were preconditioned with methanol followed by the addition of $100 \mu \mathrm{l}$ of each sample.

Two millilitres of each solvent in the order methanol, ethyl acetate and hexane, was added to the columns and the eluents were separately collected in 2-ml fractions into $10 \mathrm{ml}$ vials and then evaporated to dryness under a stream of nitrogen gas. The weight of each extract recovered after clean-up was determined and reconstituted in appropriate volume of solvent to obtain a $10-\mathrm{mg} / \mathrm{ml}$ solution. In order to determine the solvents that the selected insecticides best eluted in, the insecticide standards were similarly fractionated by SPE using the three eluting solvents, methanol, ethylacetate and hexane.

\section{Determination of residue levels}

The method of Meyer et al. (1982) was used with minor modifications. Brine shrimp eggs, purchased from Brine shrimp Direct, California, USA were cultured in a hatching tank containing filtered sea salt water and placed under light. After $48 \mathrm{~h}$ the hatched and mature shrimp nauplii were then used for lethal toxicity assay. Five microlitres of each extract was aliquoted separately into $10 \mathrm{ml}$ vials (with marking at $5 \mathrm{ml}$ level) and evaporated to dryness under 
a stream of nitrogen gas. The residue was dissolved in $40 \mu \mathrm{l}$ of acetone and $2 \mathrm{ml}$ of the saline water was added to each vial to make the initial solution of the extract or insecticide standard. Ten shrimp nauplii were transferred to each vial and the volume made up to the $5 \mathrm{ml}$ mark with sea water. The control contained only acetone and sea water. The set up was placed under light and number of dead shrimp nauphii after $24 \mathrm{~h}$ was recorded. Each test was replicated four times.

\section{Data analysis}

All data was analyzed using Minitab version 12 for Windows ${ }^{\mathrm{TM}}$ software. Abbott's formula (Abbott, 1925) was used to correct for natural mortality in mosquitoes and brine shrimp nauplii. $\mathrm{The}_{\mathrm{KT}_{50}}$ and $\mathrm{KT}_{95}$ values for mosquitoes were estimated from the time-mortality regression using probit analysis (Finney, 1971). Standard dosage-brine shrimp mortality curves for the insecticide standards were obtained and then used to estimate their concentrations in soil and water extracts.

\section{Results}

\section{Mortality}

Apart from permethrin to which the 'Kisumu' strain demonstrated $96 \%$ mortality, full susceptibility to deltamethrin, DDT and malathion was observed (Fig. 1). The wild Anopheles populations for Airport and Korle-Bu, like the 'Kisumu' population, demonstrated complete susceptibility (100\% mortality) to the organophosphate, malathion. Contrarily, the wild populations gave lower mortality rates against the pyrethroids, deltamethrin (77\% for Airport and $73 \%$ for Korle-Bu) and permethrin (25\% for Airport and $45 \%$ for Korle-Bu), with the lowest mortality being recorded for DDT (11\% for Airport and $16 \%$ for Korle-Bu).

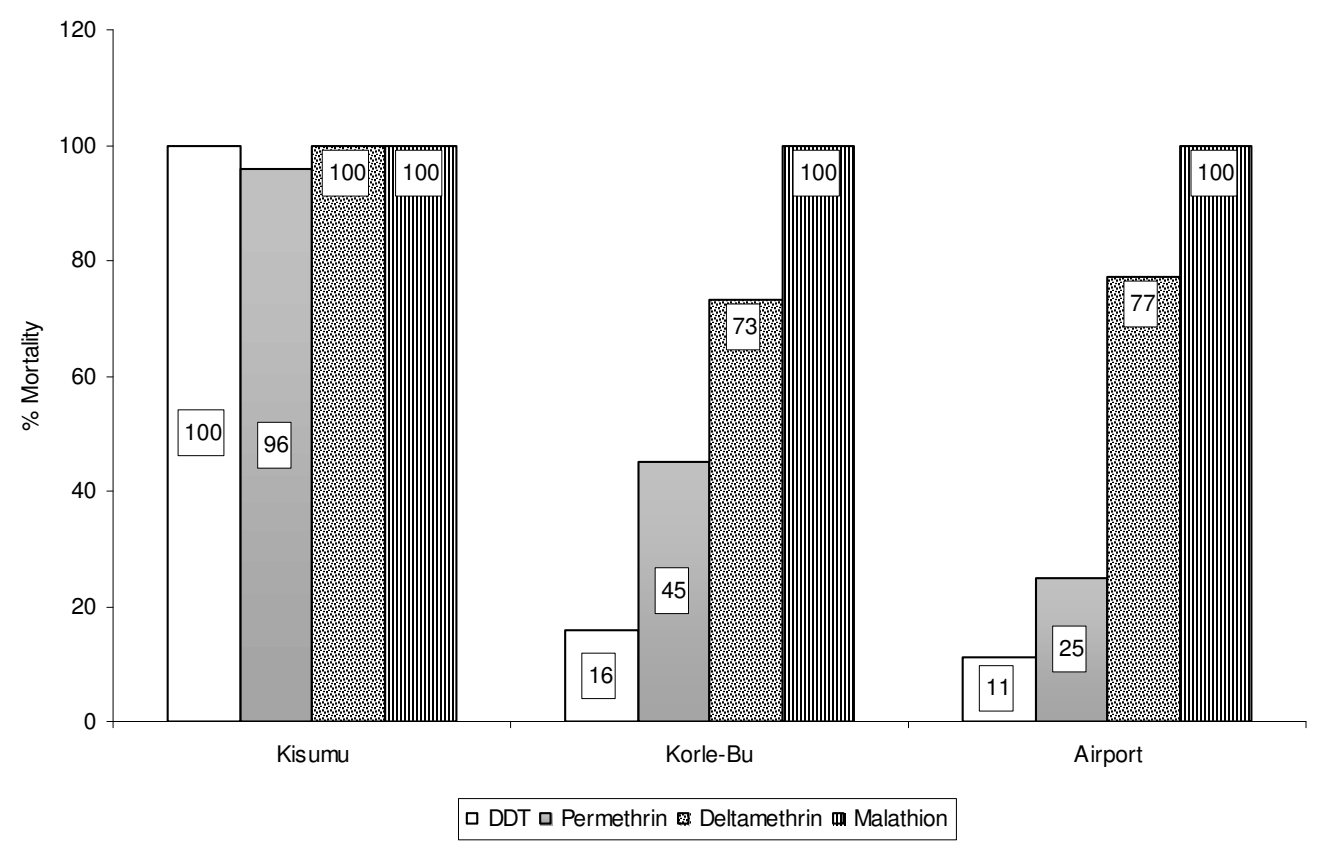

Fig. 1. Susceptibility of 'Kisumu' strain and wild populations of A. gambiae from cabbage growing areas in Korle Bu and Airport to selected insecticides

Knockdown

The $\mathrm{KT}_{50}$ and $\mathrm{KT}_{95}$ values obtained for the susceptible 'Kisumu' strain were compatible with the susceptibility of these mosquitoes to the tested insecticides. The $\mathrm{KT}_{50}$ of the two wild populations were compared with those obtained for the susceptible mosquitoes to obtain the 
resistance ratio. The resistant ratio $\left(\mathrm{RR}_{50}\right)$ at $\mathrm{KT}_{50}$ level for permethrin was 10.6 and 9.4 for Airport and Korle-Bu, respectively, while relatively lower levels were obtained for deltamethrin (Table 1). The $\mathrm{RR}_{50}$ for DDT was not calculated because the number of mosquitoes knocked down in the wild populations at the end of the exposure time was less than $15 \%$.

TABLE 1

Knockdown time (KT) and resistance ratio for bioassays of the susceptible and two wild populations of female A. gambiae

\begin{tabular}{|c|c|c|c|c|c|}
\hline Insecticide & Population & $K T_{50}(\min )$ & $K T_{95}$ min) & $N$ & $R R_{50}$ \\
\hline \multirow[t]{3}{*}{ Permethrin $(0.75 \%)$} & Kisumu & 9.6 & 28.8 & 100 & - \\
\hline & Airport & 101.5 & 151.6 & 100 & 10.6 \\
\hline & Korle-Bu & 89.8 & 159.8 & 100 & 9.4 \\
\hline \multirow[t]{3}{*}{ Deltamethrin $(0.05 \%)$} & Kisumu & 17.3 & 33.0 & 100 & - \\
\hline & Airport & 54.7 & 89.1 & 100 & 3.2 \\
\hline & Korle-Bu & 44.8 & 82.2 & 100 & 2.6 \\
\hline \multirow[t]{3}{*}{ DDT $(4 \%)$} & Kisumu & 23.4 & 43.1 & 80 & - \\
\hline & Airport & No kd & No kd & 100 & ND \\
\hline & Korle-Bu & No kd & No kd & 100 & ND \\
\hline
\end{tabular}

Resistance ratio was calculated at $\mathrm{KT}_{50}$ level with reference to the susceptible 'Kisumu' strain as $\mathrm{RR}_{50}=$ resistance ratio $\left(\mathrm{KT}_{50}\right.$ Wild $/ \mathrm{KT}_{50}$ Kisumu) at $P<0.05$.

$\mathrm{N}=$ number of treated mosquitoes; No kd = complete loss of knockdown effect $(<15 \%$ of mosquitoes knockdown after $1 \mathrm{~h}$ of exposure); ND = Indeterminate.

\section{Mosquito species and molecular forms}

Of the 60 A. gambiae s.s. identified from Korle- $\mathrm{Bu}, 10(17 \%)$ were found to be the $\mathrm{S}$ form while $50(83 \%)$ were the $\mathrm{M}$ form. In contrast, out of the $60 \mathrm{~A}$. gambiae s.s. identified from Airport, only three (5\%) were the $\mathrm{M}$ form while 57 (95\%) were the $\mathrm{S}$ form.

Residue levels

Relative to the other pyrethroids, cypermethrin was observed to have the lowest $\mathrm{LC}_{50}$ value. The concentrations of toxic components in extracts were estimated from log concentration-brine shrimp mortality regression equations of cypermethrin, chlorpyrifos and pirmiphos-methyl. Concentration of residues in hexane fractions of extracts were estimated from the calibration curve of cypermethrin while calibration curve of chlorpyrifos and pirmiphos-methyl were used for determina-tion of residues in the methanol and ethyl acetate fractions, respectively. The concen-tration of active residue in fraction (residual bioactivity) was estimated as a percentage of estimated concentration of toxic component relative to the lethal concen-tration of $10 \mu \mathrm{g} / \mathrm{ml}$, i.e. concentration found to give at least $20 \%$ brine shrimp mortality (Tables 2 and 3). Run-off extracts from Korle-Bu area showed mortality ranging from 20-100\% while for Airport area, brine shrimp mortality ranged from $28-50 \%$ at $10 \mu \mathrm{g} / \mathrm{ml}$ concentration. For soil extracts, mortality was between $5-75 \%$ and $5-30 \%$ at $10 \mu \mathrm{g} / \mathrm{ml}$ concentration for Korle-Bu and Airport areas, respectively.

There was variation in residual bioactivity in the three extracting solvents for both run-off and soil extracts within and between the two study areas (Tables 2 and 3). Methanolic fractions of run-off extracts at $10 \mu \mathrm{g} / \mathrm{ml}$ showed the lowest residual bioactivity for both sites while hexane and ethylacetate fractions recorded the highest residual bioactivity for Korle- $\mathrm{Bu}$ and Airport, 
respectively. However, the highest residual bioactivities for soil extracts were recorded for the methanol and ethyl acetate fractions for Korle-Bu and ethyl acetate and hexane fractions for Airport area. A tenth dilution of both soil and run-off water extracts in either site essentially recorded low or no activity. The total residue concentration for both run-off and soil was higher (Table 4) in Korle-Bu relative to the Airport area.

TABLE 2

Residual bioactivity in run-off and soil extracts from Korle Bu, Ghana

Extracting solvent

$\%$ Residual bioactivity* Concentrations of extracts

\begin{tabular}{|c|c|}
\hline & \\
\hline $10 \mu \mathrm{g} / \mathrm{ml}$ & $1 \mu \mathrm{g} / \mathrm{ml}$ \\
\hline
\end{tabular}

$\begin{array}{lllll}\text { Methanol }^{\mathrm{a}} & 0.7 & \text { Low } & 0.2 & \text { Low } \\ \text { Ethylacetate }^{\mathrm{b}} & 5.7 & \text { Low } & 2.4 & \mathrm{~N} \\ \text { Hexane }^{\mathrm{c}} & 8.2 & \text { Low } & \text { Low } & \mathrm{N}\end{array}$

${ }^{\text {a }}$ Methanol fractions estimated from the standard curve for chlorpyrifos.

${ }^{\mathrm{b}}$ Ethylacetate fractions estimated from standard curve for pirimiphos-methyl.

${ }^{\mathrm{c}}$ Hexane fractions estimated from standard curve for cypermethrin.

$*$ Residual bioactivity = Estimated concentration $(\mu \mathrm{g} / \mathrm{ml})$ of toxic component/lethal concentration for each fraction.

**Lethal concentration $=10 \mu \mathrm{g} / \mathrm{ml}$ (concentration found to give at least $20 \%$ mortality).

Low $=$ Residual bioactivity so low it could not be estimated from calibration curve.

$\mathrm{N}=$ No residual bioactivity.

TABLE 3

Residual bioactivity in run-off and soil extracts from Accra Airport, Ghana

Extracting solvent

$\%$ Residual bioactivity*

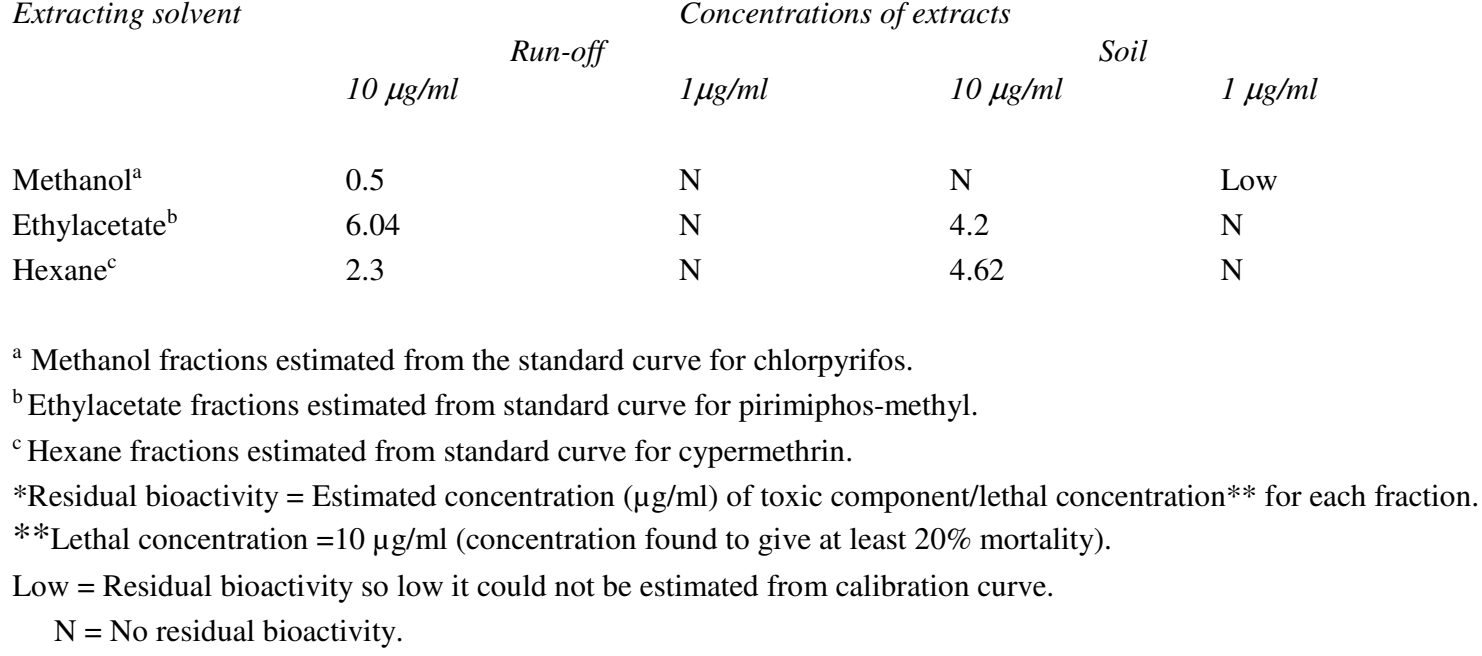

TABLE 4

Estimates of insecticide residue levels in run-off and soil from cabbage growing areas within Korle-Bu and Airport

Site
Total weight* of
Run-off
Residue $^{a}$
Total weight of
Soil

West African Journal of Applied Ecology, Vol. 12, 2008 


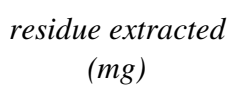

Korle-Bu

Airport

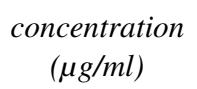

25.7

24.3 residue extracted

( $m g$ )

8.8

4.0 residue level

$(\mathrm{mg} / \mathrm{g})$

0.89

0.43

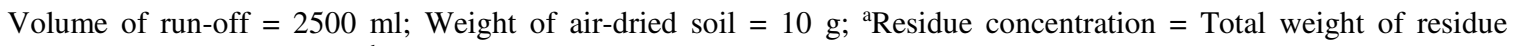
extracted/volume of run-off; ${ }^{\text {b}}$ Total estimated residue level = Total weight of residue extracted/weight of air dried soil.

*Total weight of residue is the average of four replicates.

\section{Discussion}

Bioassay data obtained for permethrin, deltamethrin, malathion and DDT confirmed resistance in mosquitoes population in Accra as previously reported by Adasi et al. (2000) and Adeniran (2002). Relative to the susceptible strain, the wild populations were observed to be highly resistant to the selected pyrethroids and DDT but showed full susceptibility to malathion. The increase in knockdown time was more marked with permethrin than deltamethrin. For example, in the Airport population, the $\mathrm{KT}_{50}$ for permethrin increased by 10.6-fold but only 3.6-fold for deltamethrin while the $\mathrm{KT}_{50}$ for Korle-Bu population increased by 9.4-fold and 2.6-fold for permethrin and deltamethrin, respectively. These results agree with earlier reports that permethrin is a better indicator of knockdown-based resistance than deltamethrin (Chandre et al., 1999b). The reduced mortality with deltamethrin in populations displaying a very high permethrin resistance suggests that $k d r$ mutation confers cross resistance to various pyrethroids. Cross-resistance to DDT was observed in these populations, although these cabbage farmers have not used this insecticide for pest control.

Resistance to DDT must have occurred because of similarity in the mode of action of DDT and pyrethroid, which is basically on the voltage-dependent sodium channel of nerve (Brooke et al., 1999; Bloomquist, 1996). Extensive use of pyrethroids for control of insect pests of cabbage may explain the high level of resistance to pyrethroids observed in these A. gambiae populations (Odhiambo, 2005). Molecular identification of A. gambiae s.l. revealed only A. gambiae s.s. as the sibling species. These results are consistent with that of other studies carried out in Accra (Adasi et al., 2000; Adeniran, 2002). Both the 'M' and 'S' molecular forms of A. gambiae s.s. were present and occurred in sympatry across the two collection sites. Unlike the Korle-Bu area, the ' $\mathrm{S}$ ' form occurred at higher frequencies than the ' $\mathrm{M}$ ' form in the Airport area, and this has serious implications for malaria control efforts since the ' $\mathrm{S}$ ' form has been strongly associated with the $k d r$ mechanism of resistance (Chandre et al., 1999b).

Brine shrimp lethality was observed in both soil and run-off extracts, i.e. $10 \mu \mathrm{g} / \mathrm{ml}$ from the two sites, indicative of the presence of insecticide residues in these extracts. The absence or low residual activity, recorded in a 10th dilution of soil and run-off extracts from both sites, suggest that $10 \mu \mathrm{g} / \mathrm{ml}$ is the concentration at which biological activity is observed. Based on the results obtained by differential fractionation studies of standard insecticides, using SPE, the bulk of insecticide residues in run-offs and soil extracts from cabbage farms in the two sites are likely to be pyrethroids and organophosphates, which agrees with the insecticide use pattern reported in Accra (Ninsin, 1996; Odhiambo, 2005). The variation of residual bioactivity between the two sites may be explained by the different farming practices of individual cabbage growers whose choice of pesticide and application rate might be different, depending on the level of insect pest infestation encountered on their farms (Ninsin, 1996; Odhiambo, 2005).

Generally, residual activity was observed to be higher in run-off than in soil extracts within Korle- $\mathrm{Bu}$ and Airport areas. The bulk of pesticide residues in soil have been reported to be confined to the upper $5 \mathrm{~cm}$ of the topsoil and agrochemicals in soil can move from the surface when they are dissolved in run-off water, or when they percolate down through the soil (FAO,

West African Journal of Applied Ecology, Vol. 12, 2008 
2000). This may explain the differences in residual activity of soil and run-off extracts observed in this study. It has been reported that the persistence of a pesticide in the soil depends on the soil's $p \mathrm{H}$, texture and microoraganisms (El Beit et al., 1981). It is, therefore, likely that the variation in residue levels in soil extracts from the two sites may be due to differences in the physiochemical properties of the different soils.

No correlation was, however, observed between the residual bioactivity and total residue level and the resistance levels in the A. gambiae s.s. populations in the two study sites. For instance, in the Airport Residential Area, the mosquitoes showed a high level of resistance to permethrin, deltamethrin and DDT relative to the Korle-Bu population. In contrast, the residual activity and total residue level were observed to be higher for the Korle-Bu than for the Airport areas. Mechanisms of resistance are known to develop as a result of long periods of exposure to particular insecticides (Chandre et al., 1999a). Thus, the increase in knockdown resistance may have evolved due to prolonged exposure to sub-lethal doses of the organophosphates and pyrethroids within these farming environ over time. The high level of resistance observed in $A$. gambiae from the Airport area, accom-panied by lower residue levels, indicates that resistance might have been selected for a longer period of time, since cabbage is grown in this area all year round and the area has been under cultivation for close to 30 years (Odhiambo, 2005).

Soil and run-off water may not have much accumulation of insecticide residues at the Airport area partly because of good drainage and partly because of observance of better agronomic practices by farmers at the Airport area compared to those at Korle-Bu (Odhiambo, 2005). Some farmers in the Airport area use water drawn from deep wells and also water running through the big drains to the Odaw river. Farmers at Korle-Bu, however, obtain water mostly from shallow wells. Furthermore, the frequency of application of insecticides by individual farmers in the two sites may be different, resulting in different levels of selection pressures on the mosquitoes. Thus, pools of water in the farms which may serve as breeding places may contain varying levels of insecticide residues, leading to the differences noted in the development or enhancement of resistance in mosquito larvae, since insecticides used by these cabbage farmers for crop protection are similar to those used for vector control programmes.

The study indicates the role of agricultural use of insecticides in the build up of resistance in malaria vectors, with its attendant implications. There is need, therefore, to consider the role of agricultural use of insecticides and farming practices in resistance management strategies for malaria vectors in order to improve the effectiveness of malaria control pro-grammes. Such studies will provide useful information for planners and implementers of malaria control programmes in Ghana.

\section{Acknowledgement}

The authors would like to express their sincere gratitude to DAAD, for the offer of scholarship to Olivia A. Achonduh, and to Noguchi Memorial Institute for Medical Research, University of Ghana, for their support.

\section{References}

Abbott W. S. (1925). A method of computing the effectiveness of an insecticide. J. econ. Ent. 18: 265-267.

Adasi K., Wilson M. D. and Boakye D. A. (2000). Studies on insecticide usage and pyrethroid resistance in populations of An. gambiae s.s. (Diptera; Culicidae) in the Greater Accra Region of Ghana. WHO-MIM Conference on Insecticide Resistance, Harare, Zimbabwe.

Adeniran T. A. (2002). Studies on insecticide usage and pyrethroid resistance in populations of Anopheles gambiae s.s (Diptera: Culicidae) in the Greater Accra Region of Ghana. (MPhil. Thesis.) University of Ghana, Legon. 136 pp.

Afun J. V. K., Braimah H., Owusu-Akyaw M., Cudjoe A. R., Dixon G. A. and Kissiedu A. F. K. (1992). Integrated Pest Management in Ghana. Paper prepared for I.P.M. Workshop; West Africa, Accra, 27th April - 1st May, 1992.

Bloomquist J. R. (1996). Ion channels as target for insecticides. A. Rev. Ent. 41: 163-190. 
Brempong-Yeboah C. Y. (1992). Report of Workshop on Vegetable Production on the Accra Plains of Ghana. Crop Science Department, University of Ghana, Legon, Ghana.

Brooke B. D., Hunt R. H., Koekemoer L. L., Dossou-Yovo J. and Coetzee. M. (1999). Evaluation of polymerase chain reaction assay for detection of pyrethroid insecticide resistance in a malaria vector species of the Anopheles gambiae complex. J. Am. Mosq. Contr. Ass. 15: 565-568.

Chandre F., Darriet F., Manga L., Akogbeto M., Faye O., Monchet J. and Guillet P. (1999a). Status of pyrethroid resistant in Anopheles gambiae sensu lato. Bull. WHO. 77(3): 230-234.

Chandre F., Manguin S., Brengues C., Dossou-Yovo J., Darriet F., Diabate A., Carnevale P. and Guillet P. (1999b). Current distribution of a pyrethroid resistance gene $(k d r)$ in malaria vector species of Anopheles gambiae complex from West Africa and further evidence for reproductive isolation of mopti form. Parasitologia 41: 319322.

Diabate A., Baldet T. Chandre F., Akogbeto M., Gimiguenide R. T., Darriet F., Bregues C., Guillet P., Hemingway J., Small G. J. and Hougard J. M. (2002). The role of agricultural use of insecticides in resistance to pyrethroids in Anopheles gambiae s.l. in Burkina Faso. Am. J. trop. Med. Hyg. 67(6): 617-22.

Diabate A., Brengues C., Baldet T., Dabire K. R., Hougard J. M., Akogbeto M., Kengne P., Simard F., Guillet P., Hemingway J. and Chandre F. (2004). The spread of the Leu-Phe $k d r$ mutation through Anopheles gambiae complex in Burkina Faso: genetic introgression and de novo phenomena. Trop. Med. int. Hlth 9(12):1267-1273.

Dickson K. B. and Benneh G. (1988). A new geography of Ghana. Longman Group, London. pp. 17-29.

El Beit I. O. D. Wheeloock J. V. and Cotton D. E. (1981). Factors that affect soil residues of dieldrin, endosulfan, gamma-HCH, dimethoate and pyloran. Ecotoxicol.Envir. Saf. 5: 135-160.

Fanello C., Santolamazza F. and della Torre A. (2002). Simultaneous identification of species and molecular forms of Anopheles gambiae complex by PCR-RFLP. Med. Vet. Ent. 16: 461-464.

FAO (2000). Assessing Soil Contamination: A Reference Manual. FAO Pesticide Disposal Series. Food and Agriculture Organization of the United Nations, Rome.

Finney J. D. (1971). Probit Analysis, 3rd edn. Cambridge University Press. Cambridge. 383 pp.

Handa S. K., Agnihotri N. P. and Kulshrestha G., ed. (1999). Pesticide Residue Significance, Management and Analysis. Research Periodicals and Book Publishing Hhouse, Texas, USA. pp. 138-140.

Klinkenberg E. and Boelee E. (2002). Research priorities on malaria and agriculture in West and Central Africa. Workshop Documentation of the SIMA WCA Sstakeholder Consultation, IITA, Ibadan, Nigeria, 18-20 March 2002. SIMA Document 1. International Water Management Institute. Colombo, Sri Lanka.

Lacey L. A. and Lacey C. M. (1990). The medical importance of riceland mosquitoes and their control using alternatives to chemical insecticides. J. Am. Mosq. Contr. Ass. 6: Supplement 2.

Meyer B. N., Ferrigni N. R., Putman J. E., Jacobsen L. B., Nichols D. E. and McLaughlin J. L. (1982). Brine shrimp. A convenient general bioassay for active plant constituent. Planta med. 45: 31-34.

Ninsin K. D. (1996). Insecticide use patterns and residue levels on cabbage Brassica olerecea var. capitata $L$. cultivated within the Accra - Tema Metropolitan Area of Ghana. (MPhil. Thesis.) University of Ghana, Legon, Ghana. 13 pp.

Odhiambo J. A. O. (2005). Insecticide resistance in diamondback moth, Plutella xyllostella from selected cabbage farms associated with pyrethroid and organophosphate use in southern Ghana. (MPhil. Thesis.) Insect Science Programme, University of Ghana, Legon, Ghana. $176 \mathrm{pp}$.

Rand G. M., Wells P. G. and Mecarty L. S. (1995). Introduction to Aquatic Toxicology. In Fundamentals of Aquatic Toxicology. (G. M. Rand, ed.), pp. 3-66. Taylor and Francis, Washington.

Roberts D. R. and Andre R. G. (1994). Insecticide resistance issues in vector-borne disease control. Am. J. trop. Med. Hyg. 50, Supplement: 21-34.

Scott J. A., Brogdon W. G. and Collins F. H. (1993). Identification of single specimens of Anopheles gambiae complex by polymerase chain reaction. Am. J. trop. Med. Hyg. 49: 520-529.

SIMA (2003). CGIAR System-wide Initiative on Malaria and Agriculture (SIMA) Framework Document. 23 pp.

Singh S., Dureja P., Kumar S. and Jain M. C. (1999). Persistence of \pm and ${ }^{2}$ isomers of endosulfan and endosulfan sulfate in diverse soils of India as influenced by flooding. J. envir. Sci. Hlth., B-34: 965-974.

Varca M. L. (2002). Impact of agrochemicals on soil and water quality. Pesticide Toxicology and Chemistry Laboratory, National Crop Protection Center, University of the Philippines at Los Banos College, Laguna 4031, Philippines. 7 pp. 